\title{
Frequency of Toxocariasis among Patients Clinically Suspected to Have Visceral Toxocariasis: A Retrospective Descriptive Study in Sri Lanka
}

\author{
Devika Iddawela, ${ }^{1}$ Kiruthiha Ehambaram, ${ }^{1}$ Dhilma Atapattu, ${ }^{1}$ \\ Kalyani Pethiyagoda, ${ }^{2}$ and Lakmalee Bandara ${ }^{1}$ \\ ${ }^{1}$ Department of Parasitology, Faculty of Medicine, University of Peradeniya, Peradeniya, Sri Lanka \\ ${ }^{2}$ Department of Community Medicine, Faculty of Medicine, University of Peradeniya, Peradeniya, Sri Lanka
}

Correspondence should be addressed to Dhilma Atapattu; dhilmaa@yahoo.com

Received 7 July 2017; Revised 13 October 2017; Accepted 17 October 2017; Published 6 December 2017

Academic Editor: José F. Silveira

Copyright (C) 2017 Devika Iddawela et al. This is an open access article distributed under the Creative Commons Attribution License, which permits unrestricted use, distribution, and reproduction in any medium, provided the original work is properly cited.

Introduction. Human toxocariasis is caused by several species of the nematode Toxocara. Two common clinical syndromes are ocular and visceral larva migrans. Objectives. To determine the Toxocara antibody positivity in clinically suspected VLM patients and to describe demographic factors and clinical manifestations of seropositive patients. Methods. 522 clinically suspected patients were studied between 1993 and 2014. Relevant data was gathered from referral letters. Serum samples were subjected to Toxocara antigen ELISA. Results. Overall, seropositivity was 50.2\% (262), of which 109 (40.8\%) were positive at high level of Toxocara antibody carriage and $153(58.4 \%)$ were positive at low levels. The seropositives ranged from 3 months to 70 years $($ mean $=7.8)$. Younger age group had higher levels of seropositivity and it was statistically significant. Majority of children under 5 years were seropositive (47.7\%, $n=125)$. Seropositivity was common in males $(55.3 \%, n=145)$. Clinical manifestations of seropositives include lymphadenopathy (24.1\%) skin rash (22.5\%), dyspnoea (21.7\%), fever (21\%), hepatosplenomegaly (9.2\%), and abdominal pain (3.8\%). 197 (75.2\%) seropositive cases had eosinophilia. These symptoms were not statistically significant. Conclusions. This study confirms toxocariasis as an important cause of childhood ill health identifying common clinical symptoms recommending preventive measures to limit transmission.

\section{Introduction}

Toxocariasis, a disease caused by zoonotic roundworms Toxocara cati and/or Toxocara canis belonging to cats and dogs, respectively, is highly prevalent in many developing countries. Among all different species, T. canis is the most important of the parasites causing toxocariasis in humans [1]. Soil contamination with infective eggs is very important in the transmission of toxocariasis to humans [2]. Food borne infection through undercooked infected meats has been documented, although this is a rare route of infection $[3,4]$. The risk of acquiring infection is increased with dog ownership, geophagia [5-7], age, geographical location (rural areas), and poor socioeconomic status [8, 9]. Toxocara spp. cannot develop to the adult worm in humans and remain restricted to the larval form. The migrating larvae cause extensive damage in the organs involved and the condition, characterized by various clinical manifestations, is known as larva migrans.

The clinical spectrum of human toxocariasis ranges from asymptomatic cases to systemic infections. The recognized clinical manifestations include visceral larva migrans (VLM), ocular larva migrans (OLM), covert toxocariasis, and asymptomatic toxocariasis [10]. The clinical syndrome of VLM may be acute or subacute, with hepatomegaly, splenomegaly, pyrexia, gastrointestinal symptoms, cutaneous manifestations, pulmonary involvement, central nervous system involvement, and eosinophilia [11]. Clinical features associated with toxocariasis are common and nonspecific and majority of clinical features present as symptoms. Therefore diagnosis based on clinical findings is unreliable since the Toxocara larvae fail to complete their migratory cycle in the 
human; eggs are not passed in the stool. Definitive diagnosis of toxocariasis is by histological examination for Toxocara larvae in biopsy materials. But it is all most impossible to detect larvae in tissues because parasites may be few in the tissues of those infected and unless situated in an organ such as eye may be difficult or impossible to locate. Thus the confirmatory diagnosis of toxocariasis depends greatly on immunological tests.

The seroprevalence rate in the world varies from less than $10 \%[12,13]$ to more than $80 \%$ in certain developing countries $[14,15]$. Toxocara infection is more prevalent in less developed tropical countries $[11,16]$. The first seroepidemiological study on toxocariasis in Sri Lankan population which was conducted in 2003 on 1020 children in the age group 1-12 years revealed $43 \%$ of seropositivity indicating high rate of transmission [7]. There is scarcity of studies done to determine the Toxocara antibodies among clinically suspected patients. Therefore the current study was carried out to determine the seroprevalence of Toxocara antibodies among suspected VLM patients and to describe demographic factors and clinical manifestations of the seropositive patients.

\section{Methods}

2.1. Study Setting and Population. A retrospective study was carried out on all the clinical samples that were referred to the Department of Parasitology, Faculty of Medicine, University of Peradeniya, for serological diagnosis to confirm the etiological diagnosis of clinically suspected VLM patients by consultant physicians and consultant paediatricians from several teaching hospitals, general hospitals, and base hospital in Sri Lanka. All the data (age, sex, presenting complain, and other investigation results) included in the referral letters were recorded and entered into a clinical data storage computer in our department. All the patient files between the years 1995 to 2014 were retrieved and the presenting complaints of all the patients were studied and categorized. Relevant clinical and laboratory data were extracted and entered in a Microsoft excel sheet. Variables included demographic data, Toxocara antibody optical density (OD) result, and the various clinical symptoms.

This study has been exempted from ethical clearance by the Ethics Review Committee of the Faculty of Medicine, University of Peradeniya.

2.2. Detection of Toxocara IgG Antibodies. From 1995 to 2014 April all the Toxocara VLM suspect cases were diagnosed via In-House TES-ELISA developed and validated in our laboratory [17]. The microtitration plates were coated with $0.846 \mu \mathrm{g} / \mathrm{ml}$ Toxocara excretory secretory antigens and incubated at $4^{\circ} \mathrm{C}$ overnight. Plates were then washed in washing buffer (PBS with $0.05 \%$ Tween 20), postcoated with $100 \mu \mathrm{l}$ PBS containing $1 \%$ bovine serum albumin and $2.5 \%$ sucrose, and incubated at room temperature (RT) for one hour. The plates were washed five times with wash buffer. Subsequently $100 \mu \mathrm{l}$ of diluted $(1: 100)$ serum samples was added to the test well in duplicate and incubated for one hour at RT. Known negative and positive sera were used as control in each plate. Following the incubation, plates were washed three times
TABLE 1: Description of the study population by age and gender.

\begin{tabular}{lcc}
\hline Age (years) & $\begin{array}{c}\text { Males } \\
n(\%)\end{array}$ & $\begin{array}{c}\text { Females } \\
n(\%)\end{array}$ \\
\hline 0 to 4.9 & $143(45.8)$ & $76(38.2)$ \\
5 to 9.9 & $125(40.1)$ & $73(36.7)$ \\
10 to 14.9 & $33(10.6)$ & $29(14.6)$ \\
15 to 19.9 & $1(0.3)$ & $2(1.0)$ \\
$\geq 20$ & $10(3.2)$ & $19(9.5)$ \\
\hline Total & $312(100)$ & $199(100)$ \\
\hline
\end{tabular}

in washing buffer to remove unbound serum and $100 \mu \mathrm{l}$ of horse radish peroxidase conjugated anti-human IgG (Sigma Chem Co.) at a dilution of 1:5000 was added to each well. Plates were incubated for 1 hour at RT. Subsequently $100 \mu \mathrm{l}$ of the substrate o-phenylenediamine dihydrochloride and $2 \mathrm{mg}$ tablets in 3\% hydrogen peroxide solution (Sigma-Aldrich, India) were added to each well. After incubating for $20 \mathrm{~min}$ at RT, $100 \mu \mathrm{l}$ of $3 \mathrm{M} \mathrm{H}_{2} \mathrm{SO}_{4}$ was added to each to stop the reaction. The optical density (OD) at $492 \mathrm{~nm}$ was measured with an automated ELISA reader. An OD value less than or equal to 0.2 was considered as negative and that greater than or equal to 0.7 was considered positive. While the values within this range $(0.2<\mathrm{OD}<0.7)$ were considered as a light infection or past infection, the OD value $>0.7$ was considered as high positive indicating recent infection [17].

2.3. Statistical Analysis. Age and gender distribution of the population was described using parametric methods. Following this, gender and age categories and serological status classified as negative, low positive, and high positive were subjected to nonparametric methods. Additionally one-way ANOVA was applied to serology categories and mean age to confirm above results. Further analysis was carried out amalgamating low positive and high positives as one group.

Finally prevalence of clinical symptoms such as eosinophilia, cervical lymphadenopathy, generalized lymphadenopathy, presence of rash, hepatomegaly, splenomegaly, hepatosplenomegaly, fever, lower and upper respiratory tract symptoms, gastrointestinal symptoms, myalgia, arthralgia, pallor, thrombocytopenia, fits, and ecchymosis was cross tabbed with serological status and chi square test applied to each of these and tested whether these were significantly associated.

$P$ value of less than 0.05 was considered to indicate statistical significance.

\section{Results}

The study population is comprised of a total of 511 study subjects of which 312 (61.1\%) were males and 199 (38.9\%) were females (Table 1). Mean age of males was 6.5 years $( \pm 7.9)$ and for females it was 9.5 years $( \pm 12.9)$. Females were found to be significantly older than males $(F=10.88$, df $=1, P<0.001)$.

Of the total of 511 clinically suspected patients, 259 (50.68\%) were positive for presence of anti TES antibodies. Of the 259 seropositive cases $40.9 . \%(n=106)$ were positive 
TABLE 2: Description of the study population by serology and gender.

\begin{tabular}{lcc}
\hline Serology & $\begin{array}{c}\text { Males } \\
n(\%)\end{array}$ & $\begin{array}{c}\text { Females } \\
n(\%)\end{array}$ \\
\hline Negative & $158(50.6)$ & $94(47.2)$ \\
Low positive & $88(28.2)$ & $65(32.7)$ \\
High positive & $66(21.2)$ & $40(20.1)$ \\
\hline Total & $312(100)$ & $199(100)$ \\
\hline
\end{tabular}

$\chi=1.16 ; \mathrm{df}=2 ; P=0.56$.

at high level of Toxocara antibody carriage indicating recent infection $(\mathrm{OD} \geq 0.7)$. The $\mathrm{OD}$ values ranged from 0.7 to 2.708 .

Low level of Toxocara antibody carriage (OD 0.2 to 0.69 ) indicating light infection or past exposure was observed in $59.07 \%(n=153)$ of the seropositive population.

A total of $49.4 \%$ of males and $52.8 \%$ of females were found to be serologically positive. There was no statistically significant association with gender and serological positivity (Table 2).

Higher levels of seropositivity was found among the younger age groups $(<10$ years) and it was found that age was significantly associated with seropositivity (Tables 3 and 4 ).

Of a number of relevant clinical features that was prevalent, the prevalence of eosinophilia was highest (72.6\%) among the study population, followed by fever (23.3\%), lower respiratory tract symptoms (20.4\%), and ecchymosis (20.3\%). However, when considering statistical associations with serological status, generalized lymphadenopathy showed a highly significant association $(P<0.004)$ with seropositivity followed by cervical lymphadenopathy $(P<0.032)$ (Table 5$)$.

\section{Discussion}

Toxocariasis represents one of the most common parasitic zoonotic infections worldwide particularly in developing countries and some tropical islands [18]. Sri Lanka being a tropical island and one of the developing countries has been a common site for Toxocara infections. In this study, a positive antibody carriage of $50.68 \%$ was observed among the clinically suspected patients indicating this infection is common in Sri Lanka. This level of antibody carriage is higher than the $43 \%$ of seropositivity reported in a seroepidemiological study carried out in children aged between 1 and 12 year in Sri Lanka [7]. But this is much lower than the $86 \%$ reported in a rural Colombian study where the study group of 82 children was from a very low socioeconomic level [1]. In $41.6 \%$ of the study population a high level of seropositivity was observed implicating recent or heavy infection. A community based seroepidemiological study carried out in children aged 1-12 years of a rural area in Sri Lanka reported much lower rate $(16.6 \%)$ of children having recent infection [7]. Similarly a community based Venesulan study considering the seropositivity at the high cut-off titre (similar to value used in this study) showed $20 \%$ positivity for urban slum dwellers and $25.6 \%$ for the rural farming community for all ages. In our study we included only symptomatic patients. This could be the reason for high rate of recent infection reported in our study.

The age of a typical VLM patient is a child between the ages of 2 and 7 years [1]. Among all the seropositive cases $(n=262)$ we have identified a large proportion of children aged $<10$ years and the age was significantly associated with seropositivity. This was similar to another study conducted only on children which had a mean age of 7.3 years [19]. In our study, active or recent infection was common among younger children (mean age 6.15 years) compared to those (mean age 9.2 years) with past or mild infection. When Beaver first identified Toxocara larvae as the aetiological agent for VLM, he postulated that zoonotic toxocariasis was probably common, especially among children [20]. All subsequent studies support Beaver's observation. Although in most populations studied young children have exhibited the highest prevalence [21-23] some studies have failed to show the age-related correlation $[1,24,25]$. Toxocariasis predominantly affects the children due to their close contact with pet animals (dogs and cats), geophagia, poor hygienic practices, and playing in contaminated sand pits. Present study was unable to demonstrate any significant association between sex and seropositivity. This is in agreement with the studies of Thomson et al. (1986); Cortés et al. (2015) [18, 25]. In contrary to our study findings Brazil [26] and in India [27] have reported that male children were more prone to infection.

The most common symptoms which lead to a consultation with the doctor were fever, lower respiratory tract difficulties, and enlarged lymph nodes. The physician suspected a parasitic infection mainly due to eosinophilia and/or lymphadenopathy. Eosinophilia was the predominant clinical feature $(72.19 \%)$ and main predictor for clinical suspicion of toxocariasis among the study population. A prior study stated eosinophilia as a reason for performing Toxocara diagnosis [27]. Similar to our study, Fernando et al. in 2007 [28] documented a high rate of eosinophilia among seropositive paediatric population. However, there was no statistically significant association between eosinophilia and Toxocara seropositivity in our study. In conformity to our study, studies in Iran and in Brazil did not documented a statistically significant correlation between eosinophilia and Toxocara seropositivity [29,30]. Roldán et al. in 2008 [11] have documented a statistically significant association between Toxocara positive serology and eosinophilia in preschool children. Although the exact role of eosinophil cells in fighting against helminth infections is not understood, Hõrak et al. (2006) stated that the parasite manipulates the host cells to produce increased number of eosinophils thereby blocking the development of inflammatory responses [31].

In our study, there was a statistically significant association between lymphadenopathy (cervical and generalized) and seropositivity. Similarly, several studies have identified lymphadenopathy as a most frequently encountered clinical feature among Toxocara infected children [32]. Of the total seropositive population, $22.5 \%$ had skin rash and difficulty in breathing was a common presenting symptom (21.4\%) among seropositive study group. Some studies documented that T. canis infection leads to allergic sensitization [33]. Diverse manifestations including wheezing and skin 
TABLE 3: Description of the study population by serology and age groups.

\begin{tabular}{|c|c|c|c|}
\hline Age (years) & $\begin{array}{c}\text { Negative } \\
n(\%)\end{array}$ & $\begin{array}{c}\text { Low positive } \\
n(\%)\end{array}$ & $\begin{array}{c}\text { High positive } \\
n(\%)\end{array}$ \\
\hline 0 to 4.9 & $117(46.4)$ & $54(35.3)$ & $48(45.3)$ \\
\hline 5 to 9.9 & $90(35.7)$ & $65(42.5)$ & $43(40.6)$ \\
\hline 10 to 14.9 & 27 (10.7) & $21(13.7)$ & $14(13.2)$ \\
\hline 15 to 19.9 & $2(0.8)$ & $1(0.7)$ & $0(0)$ \\
\hline$\geq 20$ & $16(6.3)$ & $12(7.8)$ & $1(0.9)$ \\
\hline Total & $252(100)$ & $153(100)$ & $106(100)$ \\
\hline
\end{tabular}

TABLE 4: Description of the study population by serology and mean age.

\begin{tabular}{lccc}
\hline Serology & Mean age (years) & Range (years) & 95\% CI \\
\hline Negative & 7.32 & 0.25 to 63 & 6.13 to 8.50 \\
Low positive & 9.22 & 0.30 to 70 & 7.13 to 11.32 \\
High positive & 6.15 & 0.50 to 65 & 4.89 to 7.41 \\
\hline Total & 7.64 & 0.25 to 70 & 6.75 to 8.54 \\
\hline
\end{tabular}

$F=3.06 ; \mathrm{df}=2 ; P=0.048$

TABle 5: Prevalence of clinical features and association with serological status.

\begin{tabular}{|c|c|c|c|c|c|c|c|}
\hline Serology & $\begin{array}{c}\text { Negative } \\
n\end{array}$ & $\begin{array}{l}\text { Low } \\
\text { positive } \\
n\end{array}$ & $\begin{array}{c}\text { High } \\
\text { positive } \\
n\end{array}$ & $\begin{array}{c}\text { Total number } \\
\text { of } \\
\text { seropositives } \\
N / \%\end{array}$ & $\begin{array}{c}\text { Number of cases } \\
\text { within total study } \\
\text { population } \\
(\%)\end{array}$ & Chi-value & $\begin{array}{l}\text { Significance } \\
\quad(P)\end{array}$ \\
\hline Eosinophilia & 174 & 116 & 81 & $197(76.06)$ & $371(72.6)$ & 3.17 & 0.205 \\
\hline $\begin{array}{l}\text { Cervical } \\
\text { lymphadenopathy }\end{array}$ & 25 & 24 & 21 & $45(17.37)$ & $70(13.7)$ & 6.904 & $0.032^{*}$ \\
\hline $\begin{array}{l}\text { Generalized } \\
\text { lymphadenopathy }\end{array}$ & 41 & 10 & 8 & $18(6.9)$ & $59(11.5)$ & 10.926 & $0.004^{* *}$ \\
\hline Rash & 17 & 7 & 5 & $12(4.6)$ & $29(5.7)$ & 1.067 & 0.586 \\
\hline Hepatomegaly & 10 & 2 & 4 & $6(2.3)$ & $16(3.1)$ & - & - \\
\hline Splenomegaly & 2 & 1 & 0 & 1 & $3(0.6)$ & - & - \\
\hline Hepatosplenomegaly & 23 & 8 & 8 & $16(6.17)$ & $39(7.6)$ & 2.054 & 0.358 \\
\hline Fever & 66 & 35 & 18 & $53(20.46)$ & $119(23.3)$ & 3.563 & 0.168 \\
\hline Difficulty in breathing & 50 & 29 & 25 & $54(20.84)$ & $104(20.4)$ & 0.908 & 0.635 \\
\hline Cough & 4 & 4 & 1 & $5(1.9)$ & $9(1.8)$ & - & - \\
\hline Abdominal pain & 7 & 4 & 4 & $8(3)$ & $15(2.9)$ & - & - \\
\hline Myalgia & 6 & 5 & 5 & $10(3.8)$ & $16(3.1)$ & - & - \\
\hline Arthralgia & 11 & 10 & 1 & $11(4.2)$ & $22(4.3)$ & - & - \\
\hline Pallor & 4 & 2 & 2 & $4(1.5)$ & $8(1.6)$ & - & - \\
\hline Thrombocytopenia & 9 & 6 & 4 & $10(3.8)$ & $19(3.7)$ & - & - \\
\hline Fits & 2 & 1 & 1 & 2 & $4(0.8)$ & - & - \\
\hline Ecchymosis & 53 & 33 & 17 & $50(19.3)$ & $103(20.3)$ & 1.427 & 0.490 \\
\hline
\end{tabular}

${ }^{*, * *} P$ value $<0.05$.

ecchymosis have been attributed to toxocariasis in children in hospital-based studies in Sri Lanka $[33,34]$. Studies have shown the capability of $T$. canis to increase the vulnerability to episodic wheezing in some patients due to activation of host defense mechanism to the parasite or due to Th2-type reaction to inhaled allergens, set up by $T$. canis $[35,36]$. Several studies have proved positive correlation between asthma and Toxocara infection particularly in children [3, 37].
Another prominent symptom was fever (20.9\%) which is similar to a study conducted in 2001 [35]. A review report on toxocariasis in Japan and several other case reports also concluded that fever is a prominent symptom in patients with toxocariasis regardless of age group [38]. A community based study conducted in children in a rural area of Sri Lanka showed a significant association between fever and Toxocara seropositivity [7]. The other common symptom mentioned 
in several reports is hepatosplenomegaly which make the diagnosis of toxocariasis more likely when accompanied by history of pica and involvement of multiple systems [10, 36]. However, our study observed only $6.17 \%$ of patients with hepatosplenomegaly having seropositivity.

Number of prior studies state that muscular pain is observed in toxocariasis infection [27,39]. Although we observed several patients with myalgia the incidence was calculated up to only $4.2 \%$. Arthralgia was observed in a similar percentage of seropositive patients (4.2\%) which differs largely compared to another study that reports an incidence of $19.6 \%$ [34].

In conclusion this study reported a Toxocara aetiology in considerably large proportion of symptomatic patients. Among the suspected VLM patients, present study identifies eosinophilia, lymphadenopathy, fever, and upper respiratory tract difficulties more frequently in the seropositive group compared to the rest of the symptoms indicating that toxocariasis has caused considerable childhood morbidity in this study group and confirms the need to recognize toxocariasis as a disease entity emphasizing urgent need for implementing preventive measures. The limitation of the study is that this study is a retrospective descriptive study; therefore we were unable to follow-up these patients for clinical and serological cure. Further studies are recommended to research into these areas in children.

\section{Conflicts of Interest}

The authors report no conflicts of interest.

\section{References}

[1] L. T. Glickman and P. M. Schantz, "Epidemiology and pathogenesis of zoonotic toxocariasis," Epidemiologic Reviews, vol. 3, pp. 230-250, 1981.

[2] D. Iddawela, K. Ehambaram, and P. Bandara, "Prevalence of toxocara antibodies among patients clinically suspected to have ocular toxocariasis: a retrospective descriptive study in Sri Lanka," BMC Ophthalmology, vol. 17, no. 1, 2017.

[3] K. Nagakura, H. Tachbana, Y. Kaneda, and Y. Kato, "Toxocariasis possibly caused by ingesting raw chicken," The Journal of Infectious Diseases, vol. 160, no. 4, pp. 735-736, 1989.

[4] D. Stürchler, N. Weiss, and M. Gassner, "Transmission of toxocariasis," The Journal of Infectious Diseases, vol. 162, no. 2, pp. 571-571, 1990.

[5] C.-K. Fan, C.-W. Liao, T.-C. Kao, M.-H. Li, W.-Y. Du, and K.E. Su, "Sero-epidemiology of Toxocara canis infection among aboriginal schoolchildren in the mountainous areas of northeastern Taiwan," Annals of Tropical Medicine and Parasitology, vol. 99, no. 6, pp. 593-600, 2005.

[6] A. Łuzna-Lyskov, I. Andrzejewska, U. Lesicka, B. SzewczykKramska, T. Luty, and Z. S. Pawłowski, "Clinical interpretation of eosinophilia and ELISA values (OD) in toxocarosis," Acta Parasitologica, vol. 45, no. 1, pp. 35-39, 2000.

[7] D. R. Iddawela, P. V. R. Kumarasiri, and M. D. S. Wijesundera, "A seroepidemiological study of toxocariasis and risk factors for infection in children in Sri Lanka," Southeast Asian Journal of Tropical Medicine and Public Health, vol. 34, no. 1, pp. 7-15, 2003.
[8] D. Campos Jr., G. R. Elefant, E. Ourique de Melo e Silva et al., "Frequency of seropositivity to Toxocara canis in children of different socioeconomic strata," Journal of the Brazilian Society of Tropical Medicine, vol. 36, no. 4, pp. 509-513, 2003.

[9] K. Havasiová, P. Dubinský, and A. Štefančiková, "A seroepidemiological study of human Toxocara infection in the Slovak Republic," Journal of Helminthology, vol. 67, no. 4, pp. 291-296, 1993.

[10] Z. Pawlowski, “Toxocariasis in humans: Clinical expression and treatment dilemma," Journal of Helminthology, vol. 75, no. 4, pp. 299-305, 2001.

[11] W. H. Roldán, Y. A. Espinoza, A. Atúncar, E. Ortega, A. Martinez, and M. Saravia, "Frequency of eosinophilia and risk factors and their association with Toxocara infection in schoolchildren during a health survey in the North of Lima, Peru," Revista do Instituto de Medicina Tropical de São Paulo, vol. 50, no. 5, pp. 273-278, 2008.

[12] P. M. Schantz, "Toxocara larva migrans now," The American Journal of Tropical Medicine and Hygiene, vol. 41, 3, pp. 21-34, 1989.

[13] S. Uga, K. Ono, N. Kataoka, and H. Hasan, "Seroepidemiology of five major zoonotic parasite infections in inhabitants of Sidoarjo, East Java, Indonesia," Southeast Asian J Trop Med Public Health, vol. 27, no. 3, pp. 556-561, 1996.

[14] B. B. Chomel, R. Kasten, C. Adams et al., "Serosurvey of some major zoonotic infections in children and teenagers in Bali, Indonesia," The Southeast Asian Journal of Tropical Medicine and Public Health, vol. 24, no. 2, pp. 321-326, 1993.

[15] J.-F. Magnaval, A. Michault, N. Calon, and J.-P. Charlet, "Epidemiology of human toxocariasis in La Réunion," Transactions of the Royal Society of Tropical Medicine and Hygiene, vol. 88, no. 5, pp. 531-533, 1994.

[16] S. K. Rai, S. Uga, K. Ono, M. Nakanishi, H. G. Shrestha, and T. Matsumura, "Seroepidemiological study of Toxocara infection in Nepal," Southeast Asian J Trop Med Public Health, vol. 27, no. 2, pp. 286-290, 1996.

[17] M. D. Wijesundera, D. Iddawela, and R. P. Rajapakse, "Validation of a Toxacara ES antigen enzyme linked immunosorbent assay (TES-ELISA) for use in childhood toxocariasis in Sri Lanka," Ceylon Journal of Medical Science, vol. 46, no. 2, pp. 4550, 2017.

[18] D. E. Thompson, D. A. Bundy, E. S. Cooper, and P. M. Schantz, "Epidemiological characteristics of Toxocara canis zoonotic infection of children in a Caribbean community," Bulletin of the World Health Organization, vol. 64, no. 2, 283 pages, 1986.

[19] J. Gawor, A. Borecka, S. Dobosz et al., "Toxocariasis in children-difficult clinical problem," Przegl Epidemiol, vol. 62, no. 2, pp. 407-413, 2008.

[20] P. C. Beaver, C. H. Snyder, G. M. Carrera, J. H. Dent, and J. W. Lafferty, "Chronic eosinophilia due to visceral larva migrans; report of three cases," Pediatrics, vol. 9, no. 1, pp. 7-19, 1952.

[21] D. H. de Savigny, A. Voller, and A. W. Woodruff, “Toxocariasis: serological diagnosis by enzyme immunoassay," Journal of Clinical Pathology, vol. 32, no. 3, pp. 284-288, 1979.

[22] G. Worley, J. A. Green, T. E. Frothingham et al., “Toxocara canis infection: Clinical and epidemiological association with seropositivity in kindergarten children," The Journal of Infectious Diseases, vol. 149, no. 4, pp. 591-597, 1984.

[23] N. E. Radman, S. M. Archelli, R. D. Fonrouge, M. D. V. Guardis, and O. R. Linzitto, "Human toxocarosis. Its seroprevalence in the City of La Plata," Memórias do Instituto Oswaldo Cruz, vol. 95, no. 3, pp. 281-285, 2000. 
[24] N. R. Lynch, L. K. Wilkes, A. N. Hodgen, and K. J. Turner, "Specificity of Toxocara ELISA in tropical populations," Parasite Immunology, vol. 10, no. 3, pp. 323-337, 1988.

[25] N. N. Cortés, C. R. Núñez, B. G. L. Guiliana, P. A. H. García, and R. H. Cárdenas, "Presence of anti-Toxocara canis antibodies and risk factors in children from the Amecameca and Chalco regions of México," BMC Pediatrics, vol. 15, no. 1, article no. 65, 2015.

[26] C. R. Teixeira, P. P. Chieffi, S. A. Lescano, E. O. de Melo Silva, B. Fux, and M. C. Cury, "Frequency and risk factors for toxocariasis in children from a pediatric outpatient center in southeastern Brazil," Revista do Instituto de Medicina Tropical de São Paulo, vol. 48, no. 5, pp. 251-255, 2006.

[27] S. Dar, G. Tanveer, B. Yattoo, S. Sofi, and P. Wani, "Seroprevalence of toxocariasis in children in Kashmir, J \& K State," Iranian Journal of Parasitology, vol. 3, pp. 45-50, 2008.

[28] S. D. Fernando, W. P. Wickramasinghe, G. M. Kapilananda, R. L. Dewasurendra, J. D. Amarasooriya, and H. G. Dayaratne, "Epidemiological aspects and risk factors of toxocariasis in a pediatric population in Sri Lanka," Southeast Asian Journal of Tropical Medicine and Public Health, vol. 38, no. 6, pp. 983-990, 2007.

[29] F. Anaruma Filho, P. P. Chieff, C. R. Correa, E. D. Camargo, E. P. Silveira, and J. J. Aranha, "Human toxocariasis: Incidence among residents in the outskirts of Campinas, State of São Paulo, Brazil," Revista do Instituto de Medicina Tropical de São Paulo, vol. 45, no. 5, pp. 293-294, 2003.

[30] A. Hosseini-Safa, S. M. Mousavi, M. Bahadoran Bagh Badorani, M. Ghatreh Samani, S. Mostafaei, and H. Yousofi Darani, "Seroepidemiology of toxocariasis in children (5-15yr Old) referred to the Pediatric Clinic of Imam Hossein Hospital, Isfahan, Iran," Iranian Journal of Parasitology, vol. 10, no. 4, Article ID 26811731, pp. 632-637, 2015.

[31] P. Hõrak, L. Tummeleht, and H. Talvik, "Predictors and markers of resistance to neurotropic nematode infection in rodent host," Parasitology Research, vol. 98, no. 5, pp. 396-402, 2006.

[32] K. Mazur-Melewska, A. Mania, M. Figlerowicz, P. Kemnitz, W. Słuzewski, and M. Michalak, "The influence of age on a clinical presentation of Toxocara spp. infection in children," Annals of Agricultural and Environmental Medicine, vol. 19, no. 2, pp. 233236, 2012.

[33] L. Jayasena, M. N. Jiffry, M. Wijesundera, and R. L. Ranaweera, "The role of toxocariasis in childhood wheezing," in Proceedings of the Annual Research Sessions, pp. 119-122, Sri Lanka, 1996.

[34] V. P. Wickramasinghe, S. P. Lamabadusuriya, and M. S. Wijesundera, "Ecchymoses: an unusual manifestation of toxocariasis in children," The Ceylon Medical Journal, vol. 46, no. 4, pp. 130131, 2001.

[35] A. A. Rayes and J. R. Lambertucci, "Human toxocariasis as a possible cause of eosinophilic arthritis," Rheumatology, vol. 40, no. 1, pp. 109-110, 2001.

[36] M. U. Ferreira, G. Rubinsky-Elefant, T. G. de Castro et al., "Bottle feeding and exposure to toxocara as risk factors for wheezing illness among under-five Amazonian children: a population-based cross-sectional study," Journal of Tropical Pediatrics, vol. 53, no. 2, pp. 119-124, 2007.

[37] N. L. El-Tantawy, H. A. El-Nahas, M. M. El-Assmy, and A. M. Alsalem, "Clinicoseroepidemiological evaluation of toxocariasis in asthmatic pediatric children in Mansoura city in Egypt," Archives of Clinical Microbiology, vol. 4, no. 4:3, 2013.

[38] M. Baldisserotto, C. F. M. Conchin, M. D. G. M. Soares, M. A. Araujo, and B. Kramer, "Ultrasound findings in children with toxocariasis: report on 18 cases," Pediatric Radiology, vol. 29, no. 5, pp. 316-319, 1999.

[39] P. J. Cooper, "Interactions between helminth parasites and allergy," Current Opinion in Allergy and Clinical Immunology, vol. 9, no. 1, pp. 29-37, 2009. 

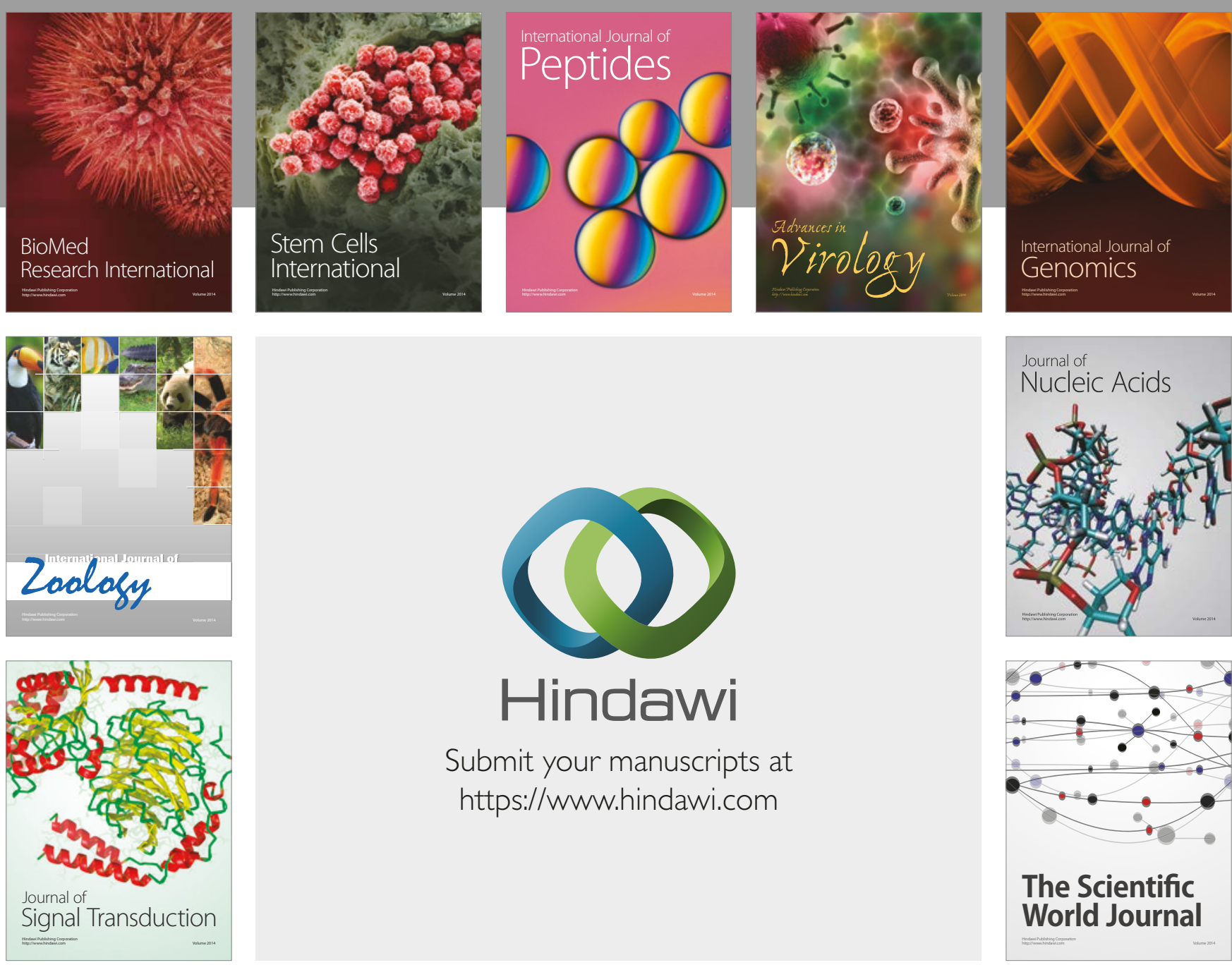

Submit your manuscripts at

https://www.hindawi.com
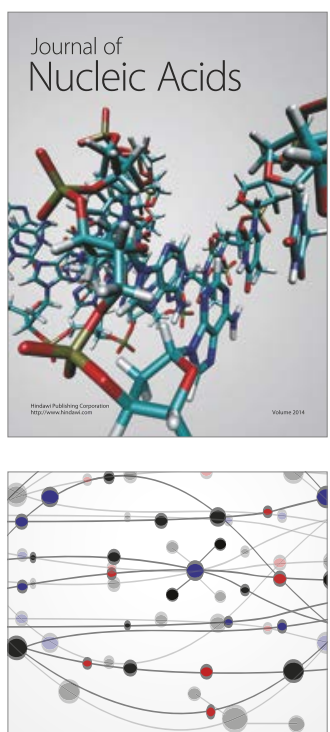

The Scientific World Journal

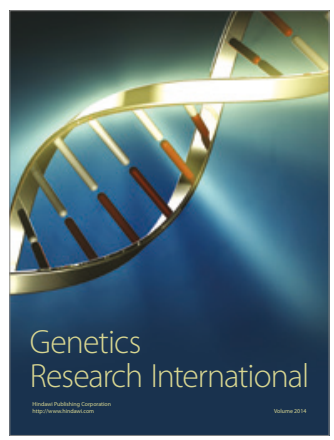

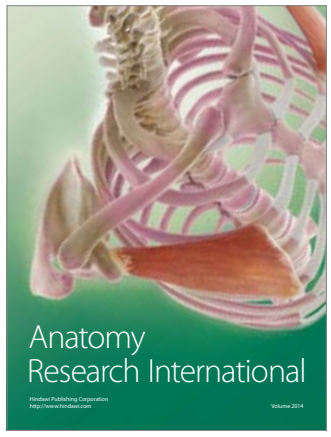

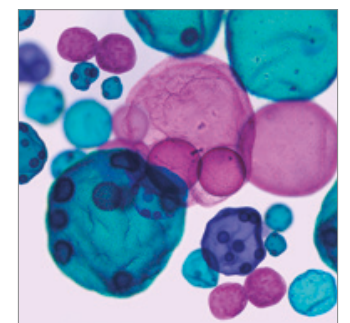

International Journal of Microbiology
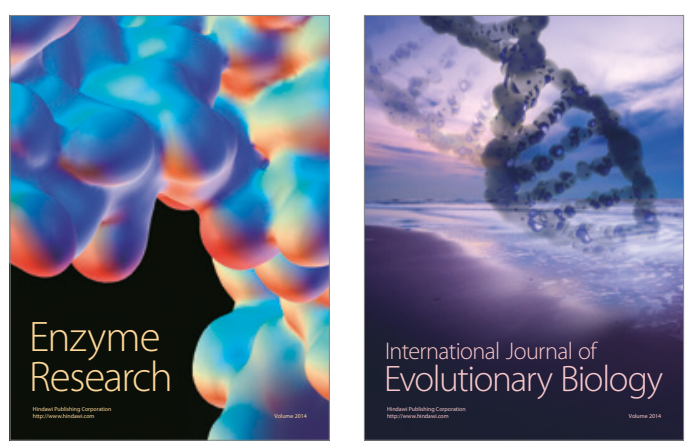
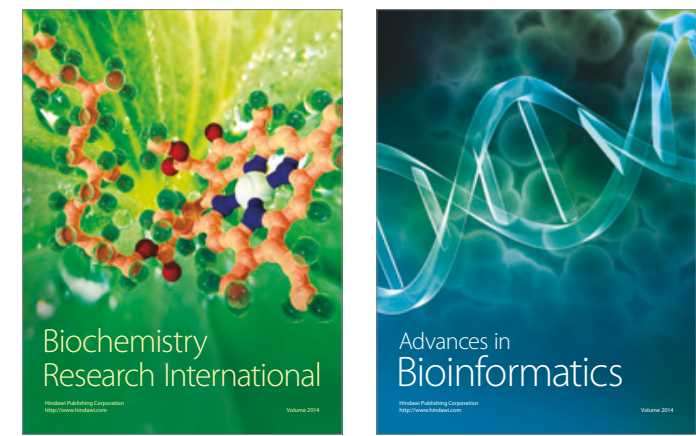

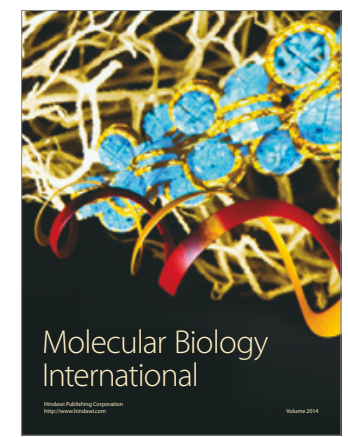

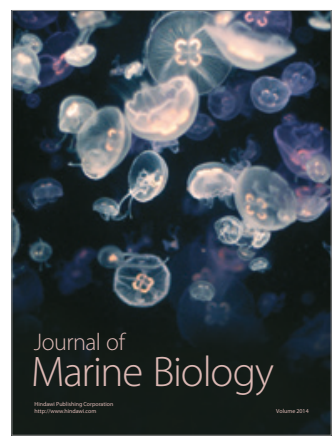

